\title{
Pelatihan Rise and Shine sebagai metode psikoedukasi: Bisakah menurunkan stigma bunuh diri?
}

\author{
Iqbal Maesa Febriawan* \\ Into The Light
}

\begin{abstract}
Abstrak
Masalah stigma masih menjadi tantangan dalam usaha promosi kesehatan mental. Salah satu metode menurunkan stigma bunuh diri yang telah diuji efektivitasnya adalah psikoedukasi melalui pelatihan. Meski demikian, konteks pengetahuan atau kompetensi lain dalam psikoedukasi selain literasi bunuh diri dan pengetahuan tentang kesehatan mental juga berpotensi menurunkan stigma. Peneliti berhipotesis bahwa stigma bunuh diri pada kandidat sukarelawan dalam komunitas pencegahan bunuh diri Into the Light menurun setelah pelatihan Rise and Shine. Desain penelitian one-group dengan pengukuran pre-test dan posttest digunakan dalam studi ini. Sebanyak 41 kandidat sukarelawan generasi kelima dari komunitas Into the Light berpartisipasi dalam studi ini. Ditemukan adanya penurunan stigma bunuh diri yang signifikan pada seluruh kandidat sukarelawan, baik untuk stigma terhadap percobaan bunuh diri $(t(40)=2,742$, pone-tailed $=0,005$, Cohen's $d=0,428)$ maupun kehilangan akibat bunuh diri $\left(t(40)=2,295, p_{\text {one-tailed }}=0,014\right.$, Cohen's $\left.d=0,358\right)$ setelah pelatihan selama empat belas minggu. Tidak ditemukan main effect $\left(F_{\mathrm{STOSA}}(1,39)=0,399, p=0,531\right.$, partial $\eta^{2}=$ 0,$010 ; F_{\text {STOSASS }}(1,39)=0,019, p=0,892$, partial $\left.\eta^{2}=0\right)$ maupun interaction effect $\left(F_{\text {STOSA }}(1,39)\right.$ $=0,674, p=0,417$, partial $\eta^{2}=0,017 ; F_{\text {STOSASS }}(1,39)=0,057, p=0,812$, partial $\left.\eta^{2}=0,001\right)$ yang signifikan atas status kandidat sukarelawan dalam pelatihan (lulus $(n=22)$ vs. tereliminasi $(n$ = 19)) terhadap penurunan stigma bunuh diri.
\end{abstract}

Kata kunci: pelatihan Rise and Shine, stigma bunuh diri, Lightbringers

\begin{abstract}
Reducing suicide stigma remains a challenging issue to be addressed. Intervention in the form of psychoeducation regarding suicide literacy and mental health knowledge might be beneficial in reducing such stigma. However, different forms of psychoeducation with various relevant knowledge and competences other than suicide literacy and mental health knowledge may also be beneficial. It was hypothesized that suicide stigma decreased post Rise and Shine training held for Into the Light's (a suicide prevention community) volunteer candidates. One-group pretest-posttest research design was used in this study. Stigma of Suicide Attempt (STOSA) and Stigma of Suicide and Suicide Survivor (STOSASS) scales were used to assess the stigma of forty-one fifth generation volunteer candidates. Post-program evaluation result showed a significant decrease of suicide stigma among all volunteer candidates after fourteen-week training, for both stigma towards attempters $(t(40)=2,742$, $p_{\text {one-tailed }}=0,005$, Cohen's $\left.d=0,428\right)$ and suicide loss survivors $\left(t(40)=2,295, p_{\text {one-tailed }}=0,014\right.$, Cohen's $d=0,358)$. There was no significant main effect $\left(F_{\mathrm{STOSA}}(1,39)=0,399, p=0,531\right.$, partial $\eta^{2}=0,010 ; F_{\text {STOSASS }}(1,39)=0,019, p=0,892$, partial $\left.\eta^{2}=0\right)$ nor interaction effect $\left(F_{\text {STоSA }}(1,39)\right.$ $=0,674, p=0,417$, partial $\eta^{2}=0,017 ; F_{\text {STOSASS }}(1,39)=0,057, p=0,812$, partial $\left.\eta^{2}=0,001\right)$ of status (passed $(n=22)$ vs. dropped out $(n=19))$ to decrease of suicide stigma.
\end{abstract}

Keywords: Rise and Shine training, suicide stigma, Lightbringers

\section{Pendahuluan}

Bunuh diri menjadi salah satu isu kesehatan jiwa yang masih tabu dibicarakan dan mengundang persepsi negatif. Keengganan untuk membicarakan soal bunuh diri di ranah publik utamanya karena stigma bunuh diri yang masih kuat di masyarakat. Stigma bunuh diri sendiri merupa-

Naskah masuk: 13 Desember 2019

Naskah diterima: 19 Juni 2020 kan pandangan yang keliru, emosi takut atau marah yang muncul, atau bahkan perlakuan diskriminatif berupa penghindaraan, penghinaan, atau bahkan tindak kekerasan pada orang yang pernah mencoba bunuh diri (Corrigan, dkk., 2017). Stigma terkait bunuh diri hingga perlakuan yang diskriminatif tidak hanya terjadi pada orang yang melakukan bunuh diri tapi juga 
orang-orang terdekat yang terdampak setelah adanya kematian karena bunuh diri (Sheehan, dkk., 2018; Scocco, Castriotta, Toffol, \& Preti, 2012). Dengan kata lain, stigma terhadap bunuh diri tidak hanya berhenti pada mereka yang mencoba atau meninggal karena bunuh diri tetapi juga mereka yang ditinggalkan karena bunuh diri.

Beberapa penelitian menunjukkan bahwa stigma bunuh diri lebih kompleks dibandingkan stigma pada isu kesehatan jiwa lainnya, apalagi pada isu kesehatan pada umumnya. Studi menggunakan obituari fiktif menunjukkan bahwa seseorang yang meninggal karena bunuh diri dipandang lebih negatif daripada orang yang meninggal karena penyakit fisik (Sand, Gordon, \& Bresin, 2013). Selaras dengan temuan sebelumnya, Sheehan, Dubke, dan Corrigan (2017) menunjukkan bahwa orang yang bunuh diri dipandang tidak dapat kembali ke kondisi sediakala bahkan ketika dibandingkan dengan orang yang terdiagnosis gangguan jiwa. Tidak berhenti di orangorang awam, stigma bunuh diri juga datang dari petugas kesehatan terutama mereka yang tidak bekerja di sektor kesehatan jiwa (Frey, 2015).

Sudah banyak usaha dengan berbagai metode yang dilakukan untuk mengurangi sikap negatif seperti stigma. Faktor seperti kontak dengan orang dengan risiko bunuh diri atau penyintas bunuh diri dianggap berperan (Maunder \& White, 2019). Selain itu, usaha seperti aktivisme sosial dan aksi kolektif bermanfaat untuk meningkatkan kesadaran terhadap kesehatan mental, walau terbatas pada konteks adanya masalah struktural masyarakat dan masalah ekonomi (MacIntyre, Ferris, Goncalves, \& Quinn, 2018). Walau pengetahuan dan literasi juga dianggap dapat mengurangi stigma (Batterham, Calear, \& Christensen, 2013; Taylor-Rodgers \& Batterham, 2014; Batterham, Han, Calear, Anderson, \& Christensen, 2019), masih diperlukan penelitian tentang efektivitas pemberian pengetahuan, literasi, atau psikoedukasi untuk berbagai konteks pelatihan terutama dengan jenis pengetahuan atau keterampilan yang berbeda (selain literasi bunuh diri dan pengetahuan tentang kesehatan mental).

Riset ini berusaha untuk menguji kembali efektivitas psikoedukasi-khususnya dalam bentuk pemberian literasi, pengetahuan, dan keterampilan secara integratif dalam pelatihan oleh komunitas Into the Light Indonesia yang diberi nama Rise and Shine. Pelatihan yang diberikan tidak hanya terfokus pada pengetahuan mengenai kesehatan mental, tetapi juga berbagai pengetahuan dan keterampilan seperti berpikir kritis, mengekspresikan diri lewat wicara publik, dan pengetahuan tentang kebijakan nasional terkait kesehatan jiwa.

\section{Alternatif intervensi untuk mengurangi stigma terkait isu kesehatan jiwa}

Beberapa metode yang sering diklaim sebagai usaha mengurangi stigma terkait isu kesehatan jiwa adalah edukasi, protes, dan kontak (Corrigan \& Penn, 2015). Protes secara terbuka untuk menyuarakan kesadaran terhadap isu bunuh diri hampir mustahil dilakukan terutama karena rasa malu yang dialami penyintas percobaan maupun kehilangan bunuh diri (Carpiniello \& Pinna, 2017; Oexle, dkk., 2018b). Sebagai alternatifnya, intervensi berbasis aktivisme sosial dilakukan untuk meningkatkan kesadaran publik mengenai isu kesehatan jiwa, khususnya pencegahan bunuh diri. Salah satunya dengan mengintervensi pemberitaan bunuh diri dengan mengeluarkan pedoman pemberitaan yang ramah terhadap publik maupun memberikan penghargaan pada jurnalis yang memberitakan bunuh diri dengan cara yang aman (cf. Dare, dkk., 2011; John, dkk., 2014).

Corrigan (2012) mengemukakan bahwa strategi komunikasi publik belum mampu mengubah sikap maupun tingkah laku diskriminatif masyarakat terhadap isu kesehatan jiwa. Salah satu penjelasan lemahnya efek intervensi media massa adalah pertimbangan terhadap efek pemirsa/audiens. Hal ini sehubungan dengan temuan bahwa strategi komunikasi publik mengenai isu kesehatan jiwa tidak berdampak yang sama terhadap populasi rentan terhadap isu tersebut (Clement, Jarrett, Henderson, \& Thornicroft, 2010). Temuan senada dikemukakan oleh KlimesDougan, Yuan, Lee, dan Houri (2009) bahwa individu yang mengalami depresi dan gejala bunuh diri justru berkurang kemungkinan pencarian bantuan profesionalnya serta menunjukkan strategi coping maladaptif seiring dengan paparan terhadap strategi komunikasi publik terkait isu kesehatan jiwa. Kedua temuan tersebut menunjukkan bahwa media massa belum menerapkan strategi komunikasi yang sesuai untuk meningkatkan kesadaran masyarakat akan isu kesehatan jiwa sehingga pandangan negatif terhadap isu tersebut masih bertahan hingga hari ini.

Intervensi kontak sendiri sudah umum dilakukan dalam rangka mengurangi stigma dan ditemukan sebagai salah satu intervensi yang dianggap efektif dalam mengurangi stigma terhadap isu sensitif (Pettigrew \& Tropp, 2006). Namun demikian, efek kontak untuk mengurangi stigma bunuh diri masih belum konklusif sehubungan dengan temuan bahwa intervensi kontak efektif mengurangi stigma bunuh diri pada populasi dewasa tetapi tidak pada remaja (Corrigan, Morris, Michaels, Rafacz, \& Rusch, 2012). Usaha mengurangi stigma bunuh diri khususnya di kalangan remaja membutuhkan perhatian khusus 
sehubungan temuan World Health Organization (2017) bahwa remaja di Indonesia cukup rentan terhadap isu bunuh diri karena $6 \%$ dari populasi penduduk berusia 13-17 tahun pernah merencanakan bunuh diri dan $4 \%$ dari populasi yang sama pernah mencoba bunuh diri setidaknya satu kali. Sehingga, diperlukan alternatif metode dalam mengurangi stigma.

\section{Psikoedukasi untuk mengurangi stigma bunuh diri}

Psikoedukasi diperlukan sebagai landasan best practice pengetahuan berbasis bukti empiris yang dibutuhkan untuk menantang pandangan yang keliru terhadap isu bunuh diri. Bentuk intervensi ini dapat dibagi berdasarkan penyampaiannya: pasif dan aktif. Menyebarkan infografis melalui situs internet maupun pamflet merupakan bentuk psikoedukasi pasif sedangkan pelatihan atau konseling merupakan contoh dari psikoedukasi aktif. Temuan Dueweke dan Bridges (2017) atas inisiatif psikoedukasi pasif berupa pamflet belum menunjukkan dampak yang signifikan terhadap penurunan stigma bunuh diri dan intensi mencari bantuan profesional kesehatan jiwa. Hasil penelitian tersebut membuka peluang bagi psikoedukasi aktif dalam usaha mengurangi stigma bunuh diri. Dari perspektif keluasan dampak dan kemudahan implementasi, pelatihan lebih dipilih dibandingkan konseling sebagai psikoedukasi aktif karena menjangkau audiens yang lebih banyak dan dapat memberikan pengetahuan yang sama bagi peserta dalam sekali waktu dibandingkan dengan konseling yang pembagian pengetahuannya perlu disesuaikan untuk setiap individu.

Efek pelatihan terhadap penurunan stigma antara lain ditemukan dalam peneltian Reavley dan Jorm (2013) yang menyampaikan bahwa terdapat bukti yang memadai bahwa pelatihan yang dilakukan secara tatap muka dapat mengubah sikap peserta terhadap isu bunuh diri. Salah satu pelatihan yang diadaptasi secara internasional terkait isu kesehatan jiwa, Mental Health First Aid, telah diteliti efektivitasnya untuk mengurangi stigma terkait isu tersebut. Selain dari kemudahan materi untuk dipahami, hasil evaluasi pelatihan tersebut menunjukkan dampak positif terhadap penurunan stigma antara lain peningkatan literasi, penurunan sikap negatif, serta berkurangnya keinginan untuk mengambil jarak fisik terhadap individu yang mengalami masalah kesehatan jiwa (Hadlaczky dkk., 2014; Szeto \& Dobson, 2010). Pengaruh positif pelatihan terhadap stigma bunuh diri ditemukan konsisten pada konteks profesional maupun sukarelawan. Pelatihan mengenai isu bunuh diri yang diberikan pada ners profesional menurunkan sikap antipati sebesar $20 \%$ serta menunjukkan penanganan krisis bunuh diri yang lebih baik dibandingkan ners yang tidak mendapatkan pelatihan (Registered Nurses' Association of Ontario, 2009; Samuelsson \& Åsberg, 2002). Temuan tersebut konsisten ditemukan pada organisasi level akar rumput (grass-root organization) sehubungan hasil penelitian dari Nejad (2016) bahwa pekerja sosial yang mendapatkan pelatihan terkait pascakematian akibat bunuh diri (postvention) menunjukkan penanganan yang lebih baik dibandingkan dengan mereka yang tidak mendapatkan pembekalan sama sekali.

Batterham, Calear, dan Christensen (2013) menjelaskan bahwa suicide literacy yang merupakan hasil dari paparan terhadap informasi terkait bunuh diri dapat menurunkan stigma terhadap perilaku bunuh diri. Ketiga peneliti tersebut juga mengemukakan bahwa diperlukan kajian terhadap intervensi yang berfokus pada peningkatan literasi untuk menurunkan stigma bunuh diri pada populasi masyarakat awam. Literasi yang didapatkan baik dari informasi faktual maupun pengalaman akan membentuk maupun mengubah cara pandang seseorang terhadap sebuah isu. Pelatihan sebagai bentuk psikoedukasi aktif menyediakan informasi tentang isu bunuh diri melalui pengetahuan faktual (riset empiris, best practice organisasi kesehatan) maupun kesempatan untuk penyintas membagikan pengalamannya. Bagi penyintas percobaan maupun kehilangan bunuh diri, pengalaman terkait bunuh diri yang pernah dijalani dapat diverifikasi dengan hard facts untuk meningkatkan literasi akan isu bunuh diri. Bagi non-penyintas, informasi faktual sekaligus pengalaman yang dibagikan penyintas percobaan maupun kehilangan bunuh diri dapat menjadi sumber literasi yang lengkap karena mencakup pengetahuan faktual maupun implisit.

\section{Pelatihan Rise and Shine.}

Sepanjang penelusuran literatur dan pengetahuan peneliti, peran pelatihan dalam menurunkan stigma bunuh diri belum pernah diteliti di populasi Indonesia-lebih khususnya dalam konteks kapasitasi sukarelawan. Bentukbentuk pelatihan yang dikemukakan sebelumnya juga masih berfokus pada penanganan krisis bunuh diri sehingga belum mencakup materi yang menyeluruh terkait isu bunuh diri di level individu hingga sistem kesehatan jiwa nasional yang bermanfaat untuk advokasi kebijakan. Salah satu cara untuk memberikan pemahaman komprehensif mengenai isu pencegahan bunuh diri adalah dengan memberikan materi suicidology, yaitu disiplin ilmu yang khusus membahas terkait isu seputar bunuh diri dan pencegahannya baik di tingkat pencegahan primer, penanganan krisis, 
maupun pasca-kematian bunuh diri (Fitzpatrick, Hooker, \& Kerridge, 2015). Muehlenkamp dan Thoen (2019) mengemukakan bahwa pemaparan materi suicidology di kelas S1 meningkatkan pengetahuan dan dukungan terhadap pencegahan bunuh diri sekaligus mengurangi sikap negatif serta stigma terhadap isu bunuh diri.

Sehubungan dengan kebutuhan untuk kapasitasi untuk sukarelawan dan dukungan bukti ilmiah yang sudah dijelaskan mengenai efektivitas psikoedukasi dalam mengurangi stigma bunuh diri, Into The Light Indonesia-sebuah organisasi sukarelawan orang muda yang berfokus pada isu pencegahan bunuh diri-mengadakan psikoedukasi dalam bentuk pelatihan yang berjudul Rise and Shine. Materi yang diberikan pada bagi para kandidat sukarelawan, yang disebut selanjutnya sebagai Lightbringers, ditujukan untuk mempersiapkan mereka menjalankan aktivitas advokasi, edukasi publik, dan intervensi berbasis komunitas dalam rangka pencegahan bunuh diri.

Materi yang menjadi modul Rise and Shine berfokus pada pemahaman tingkah laku manusia dan gejala sosial, pengantar kesehatan jiwa dan psikopatologi, pemahaman dan komunikasi hasil riset ilmiah, dan pengetahuan mengenai isu pencegahan bunuh diri di level individual hingga advokasi kebijakan. Di samping itu juga terdapat keterampilan individual yang berpotensi menjadi penyangga seperti berpikir kritis dan wicara di depan umum. Detil setiap materi disampaikan di Lampiran 1. Setiap sesi diberikan setiap akhir minggu selama 14 minggu, kecuali jika akhir minggu bertepatan dengan hari besar keagamaan atau libur nasional. Setiap akhir sesi, kandidat Lightbringers menjalani sesi dukungan kelompok singkat (brief group support session) untuk menyampaikan pandangan, perasaan, dan pemikiran sukarelawan setelah pemberian materi. Setiap materi juga diakhiri dengan post-test berupa kuis dengan pilihan ganda terkait materi yang diberikan di sesi tersebut.

Sepanjang penelusuran literatur, peneliti dapat mengklaim bahwa Rise and Shine merupakan satu-satunya pelatihan kapasitasi mengenai isu bunuh diri yang komprehensif di Indonesia, mulai dari level individu hingga kebijakan. Psikoedukasi yang dilakukan dalam rangka pencegahan bunuh diri kebanyakan mencakup materi penanganan krisis bunuh diri serta diberikan melalui informasi secara pasif maupun lokakarya satu waktu (one-time workshop) (Loreto, 2017; Rogers, dkk., 2018; Wilson \& Neufeld, 2017).

Kebaruan modul Rise and Shine terletak pada materi pelatihan yang tidak hanya membahas materi yang disebutkan sebelumnya, tetapi juga pemahaman dasar sosial-perilaku, kebijakan nasional terkait kesehatan jiwa, serta seluruh lingkup suicidology terutama aspek postvention sebagai upaya pencegahan bunuh diri tiruan setelah kejadian bunuh diri. Modul Rise and Shine juga mengikuti saran Reavley dan Jorm (2013) soal berfokus pada do's, tidak hanya pada don'ts. Hal ini bermakna bahwa modul Rise and Shine juga menekankan pada aspek promotif dari pencegahan bunuh diri di berbagai level.

Penelitian ini mencoba untuk menggali potensi pelatihan yang efektivitasnya belum banyak dieksplorasi di level perubahan sikap maupun tingkah laku (Corrigan, 2005). Temuan tersebut menjadi acuan untuk mengevaluasi pelatihan Rise and Shine dalam rangka menurunkan sikap negatif kandidat Lightbringers terhadap isu bunuh diri. Dengan bekal pengetahuan dan keterampilan yang tepat dalam memahami isu bunuh diri, intervensi lainnya seperti kontak maupun kampanye publik dapat menjadi lebih efektif. Peneliti berhipotesis bahwa stigma terhadap penyintas percobaan bunuh diri maupun penyintas kehilangan karena bunuh diri menurun pada kandidat Lightbringers setelah Rise and Shine selesai.

Dampak stigma terhadap bunuh diri sendiri beragam mulai dari keengganan untuk berelasi dengan orang yang pernah mencoba bunuh diri hingga pemikiran bunuh diri yang dimediasi oleh kekhawatiran akan diskriminasi (Lester \& Walker, 2006; Oexle dkk., 2018a). Studi kualitatif yang dilakukan Oexle dan kolega (2018b) juga menemukan bahwa efek stigma berupa perasaan kesepian, malu, dan tidak berdaya ditemukan lebih intens pada mereka yang pernah mencoba bunuh diri dibandingkan dengan individu yang mengalami masalah kesehatan jiwa lainnya. Carpiniello dan Pinna (2017) menemukan bahwa kejadian bunuh diri dan stigmanya memiliki hubungan dua arah, yang bermakna bahwa kejadian bunuh diri berimbas pada stigma bagi orang-orang yang terlibat di dalamnya sedangkan stigma terhadap isu bunuh diri menjadi salah satu faktor yang berkontribusi terhadap kejadian bunuh diri. Hal tersebut berimplikasi bahwa untuk menekan kejadian bunuh diri, salah satu faktor yang perlu ditangani adalah stigma bunuh diri itu sendiri.

Penelitian yang dilakukan Feigelman, Gorman, dan Jordan (2009) serta Cvinar (2005) secara terpisah menyimpulkan bahwa stigma juga memperberat kondisi orang-orang terdekat atas kejadian meninggal akibat bunuh diri, terutama dalam manajemen kedukaan. Kondisi tersebut ditambah dengan isu bunuh diri yang masih stigmatif membuat keluarga lebih memilih untuk diam atau tidak banyak berkomentar atas kematian akibat bunuh diri (Chapple, Ziebland, \& Hawton, 2015). Diperkuat dengan perasaan bersalah dan malu yang dialami, temuan tersebut juga mendukung pemahaman bahwa individu 
yang ditinggalkan karena bunuh diri lebih memilih untuk merahasiakan sebab kematian orang terdekatnya. Selain itu, diamnya orang terdekat setelah adanya kematian karena bunuh diri berpotensi untuk menurunkan kemungkinan mereka dalam pencarian bantuan untuk meredakan reaksi emosional atas duka yang mereka alami
(Calear, Batterham, \& Christensen, 2014). Sehingga, dari segi praktikal bisa dikatakan bahwa mengurangi stigma bunuh diri sangat penting untuk dilakukan dan psikoedukasi dari pelatihan Rise and Shine ini bisa berpotensi untuk mencapai tujuan tersebut.

\section{Gambar 1}

Alur retensi/eliminasi partisipan penelitian

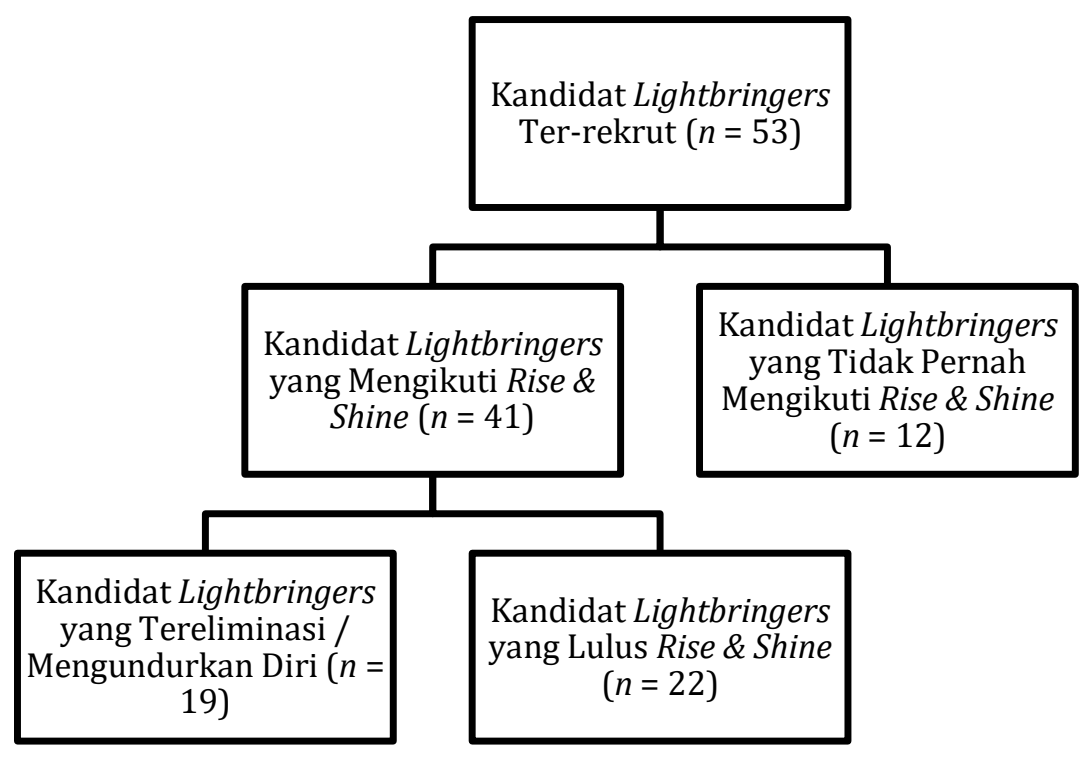

\section{Metode Penelitian}

\section{Partisipan}

Rekrutmen generasi kelima sukarelawan Into the Light Indonesia di tahun 2018 menghasilkan 53 kandidat Lightbringers. Sebelum sesi pertama pelatihan, dua belas orang menyatakan mengundurkan diri. Kedua belas orang ini tidak mengikuti pretest sehingga tidak ditindaklanjuti posttest-nya. Data dari 41 orang yang mengikuti pelatihan Rise and Shine ini dianalisis untuk membuktikan efektivitas pelatihan ini. Dari sejumlah kandidat tersebut, mayoritas di antara mereka adalah perempuan $(n=29)$, berpendidikan S1 ( $n$ = 40), dan 27 orang di antaranya adalah penyintas percobaan bunuh diri.

Salah satu aturan selama pelaksanaan pelatihan Rise and Shine adalah tidak boleh melewatkan sesi pelatihan lebih dari empat kali. Alasan dari penerapan aturan tersebut adalah pertimbangan komunitas bahwa dengan melewatkan setidaknya empat materi dari silabus Rise and Shine, sukarelawan dikhawatirkan tidak memiliki pemahaman mengenai isu bunuh diri secara utuh dan akan cukup membutuhkan usaha yang besar untuk mengejar ketertinggalan materi yang dilewatkan. Implikasinya, kandidat terpaksa gugur dari perekrutan sukarelawan ITL ketika lewat dari batasan tersebut. Selama pelaksanaan pelatihan, total 19 orang menyatakan mengundurkan diri karena absen yang melebihi batas maupun alasan pribadi, seperti tuntutan keluarga maupun manajemen waktu dengan aktivitas utama (bekerja/sekolah). Orang-orang yang mengundurkan diri selama proses pelatihan dihubungi kembali untuk mengisi kuesioner post-program setelah ada pernyataan pengunduran diri baik dari panitia maupun kandidat Lightbringers. Hingga akhir pelaksanaan pelatihan, 22 orang kandidat Lightbringers berhasil melewati seluruh rangkaian pelatihan. Analisis lanjutan terhadap efektivitas intervensi ini dilakukan untuk melihat apakah terdapat efek dari lulus maupun tereliminasi terhadap penurunan stigma bunuh diri. Alur retensi/eliminasi partisipan secara visual dapat dilihat di Gambar 1.

\section{Desain}

Studi ini menggunakan desain penelitian dengan pengukuran berulang (one group pretestposttest design) untuk melihat stigma terhadap bunuh diri sebelum dan sesudah diberikan pelatihan Rise and Shine. Sehubungan dengan kandidat Lightbringers yang tidak pernah mengikuti 
pelatihan Rise and Shine tidak merespon kembali undangan untuk mengisi kuesioner post-program, desain penelitian non-equivalent control group tidak dapat digunakan dalam studi kali ini.

\section{Prosedur}

Penelitian ini menggunakan dua alat ukur stigma bunuh diri untuk baseline dan posttraining, yaitu Stigma of Suicide Attempt (STOSA,

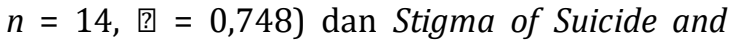
Suicide Survivor (STOSASS, $n=14$, 目 $=0,826$ ) (Scocco, Castriotta, Toffol, \& Preti, 2012). Kedua pengukuran ini saling melengkapi dimana STOSA melihat stigma terhadap individu yang pernah mencoba dan meninggal karena bunuh diri sedangkan STOSASS mengukur stigma terhadap orang sekitar (keluarga dan teman) dari individu yang memiliki kecenderungan bunuh diri. Satu item ditambahkan di pengukuran STOSA dan STOSASS mengenai stigma dari agama (dosa bunuh diri) sehubungan dengan nilai agama di Indonesia yang cukup mengakar (Sihombing, 2014). Skor STOSA maupun STOSASS merupakan penjumlahan seluruh item di masing-masing pengukuran. Informed consent diberikan di awal kuesioner yang berisi tujuan pemberian alat ukur sebagai evaluasi program psikoedukasi, risiko minimal, dan gambaran topik yang akan diukur. Pengukuran baseline dilakukan sebelum materi minggu pertama diberikan dan pengukuran posttest dilakukan seminggu setelah materi terakhir dilakukan atau 15 minggu setelah pengukuran baseline.

\section{Teknik Analisis}

Peneliti menggunakan tiga teknik statistik dalam penelitian ini. Untuk studi pendahuluan, peneliti menggunakan independent sample $t$ test untuk melihat perbedaan rerata baseline stigma pada kelompok kandidat Lightbringers yang lolos maupun tereliminasi. Coolican (2014) menyatakan bahwa salah satu asumsi yang harus terpenuhi dalam analisis desain pengukuran berulang adalah perbedaan antara data pretest dan posttest harus terdistribusi normal. Analisis normalitas data dilakukan terhadap difference score dari skor pre-and-post test pada kedua pengukuran sebelum uji hipotesis penelitian. Uji normalitas menunjukkan bahwa difference score terdistribusi normal (Shapiro-Wilk STOSA $=0,977, p=0,582$, Shapiro-Wilk STOSASS $=0,959, p=0,140$ ). Untuk menjawab hipotesis penelitian ini, peneliti menggunakan dependent-/paired-sample t-test. Efektivitas penurunan stigma bunuh diri diklaim ketika terdapat penurunan skor stigma bunuh diri yang signifikan secara statistik terhadap data baseline dan pasca-intervensi.
Analisis lanjutan untuk melihat perbedaan efek penurunan stigma pada kandidat Lightbringers yang lulus maupun tereliminasi dilakukan dengan ANOVA mixed design. Ketika dipisahkan antara kelompok yang lulus dan tereliminasi, Levene's test dilakukan terlebih dahulu untuk menguji kesetaraan varians antarkelompok. Tidak ditemukan perbedaan varians yang signifikan terhadap skor STOSA maupun STOSASS baik ketika baseline $\left(F_{\text {STоSA }}(1,39)=1,676, p=0,203\right.$; $\left.F_{\text {STOSASS }}(1,39)=0,097, p=0,757\right)$ atau postprogram $\left(F_{\text {STоSA }}(1,39)=0,223, p=0,639\right.$; $\left.F_{\text {STOSASS }}(1,39)=0,008, p=0,929\right)$ pada kandidat Lightbringers yang lulus maupun tereliminasi. Seluruh analisis dilakukan menggunakan perangkat lunak JASP versi 0.11.1.0.

\section{Hasil Penelitian}

\section{Studi Penelitian}

Analisis terhadap data baseline kandidat yang mengikuti rangkaian pelatihan Rise and Shine menunjukkan bahwa tidak ditemukan perbedaan yang signifikan dalam skor STOSA $\left(M_{\text {tereliminasi }}=24,16(S D=5,08), M_{\text {lulus }}=24,32(S D\right.$ $=4,20), t(40)=-0,106, p=0,906)$ maupun STOSASS $\left(M_{\text {tereliminasi }}=22,68(S D=5,07), M_{\text {lulus }}=\right.$ $22,32(S D=5,74), t(40)=-0,018, p=0,985)$ baik pada kandidat yang menyelesaikan Rise and Shine maupun yang tereliminasi. Gambar 2 menunjukkan visualisasi dari temuan tersebut.

\section{Evaluasi Rise and Shine}

Evaluasi yang dilakukan melalui kuis yang diberikan setiap akhir sesi pelatihan menunjukkan bahwa rata-rata persentase serapan materi dari seluruh modul terrentang mulai dari $19,6 \%-88,9 \%(M=52,6, S D=13,1)$. Rata-rata skor STOSA yang dimiliki seluruh kandidat Lightbringers menurun dari sebelum $(M=24,24, S D=$ $4,57)$ hingga selesainya Rise and Shine atau setelah lima belas minggu $(M=22,41, S D=3,71, t(40)=$ 2,742 , pone-tailed $=0,005$, Cohen's $d=0,428$ ). Hal yang sama juga terjadi pada rata-rata skor STOSASS, yang ketika awal studi memiliki nilai rata-rata $22,49(S D=5,37)$ sedangkan rata-rata skor setelah lima belas minggu adalah 20,98 ( $S D$ $=5,04)\left(t(40)=2,295, p_{\text {one-tailed }}=0,014\right.$, Cohen's $d$ $=0,358)$. Berdasarkan hasil tersebut dapat disimpulkan bahwa terdapat penurunan stigma bunuh diri yang signifikan pada seluruh kandidat Lightbringers generasi kelima setelah melalui sesi Rise and Shine. Gambar 2 memberikan ringkasan visual mengenai hasil uji hipotesis penelitian ini. Analisis lanjutan terhadap kandidat Lightbringers yang lulus maupun yang tereliminasi menunjukkan bahwa status kelulusan tidak memiliki main 
effectantar-kelompok yang signifikan $\left(F_{\text {STOSA }}(1,39)=\right.$ 0,399, $p=0,531$, partial $\eta^{2}=0,010 ; F_{\text {STOSASS }}(1,39)$ $=0,019, p=0,892$, partial $\eta^{2}=0$ ) maupun interaction effect yang signifikan dengan penurunan stigma $\left(F_{\text {STOSA }}(1,39)=0,674, p=0,417\right.$, partial $\eta^{2}=0,017 ; F_{\text {STOSASS }}(1,39)=0,057, p=$ 0,812 , partial $\left.\eta^{2}=0,001\right)$. Hasil tersebut menun- jukkan bahwa penurunan stigma yang signifikan terjadi baik pada kandidat yang lulus maupun yang tereliminasi. Detail statistik deskriptif kedua kelompok ditampilkan di tabel 1. Gambar 4 dan 5 menunjukkan visualisasi dari penurunan stigma pada kandidat yang lulus maupun tereliminasi.

\section{Gambar 2.}

Skor baseline stigma bunuh diri pada kandidat Lightbringers

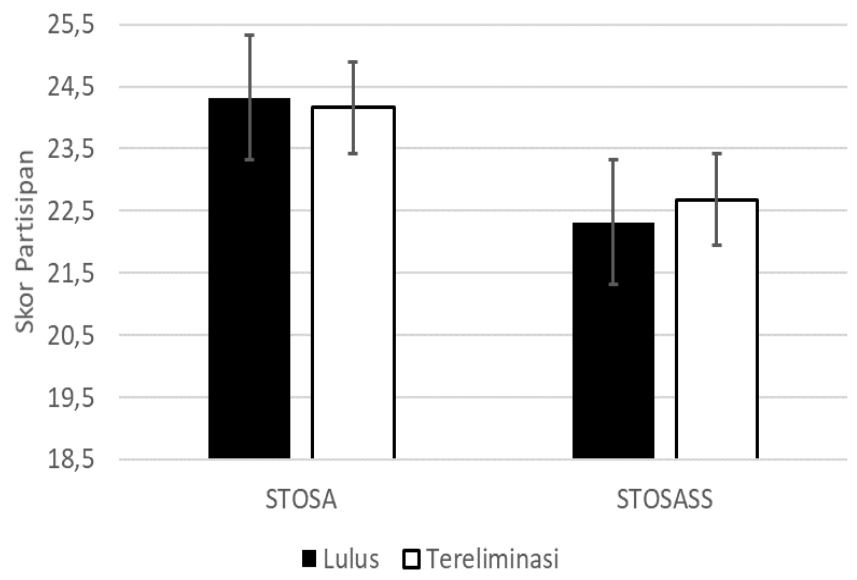

Gambar 3.

Stigma bunuh diri kandidat Lightbringers sebelum dan setelah mengikuti pelatihan Rise and Shine

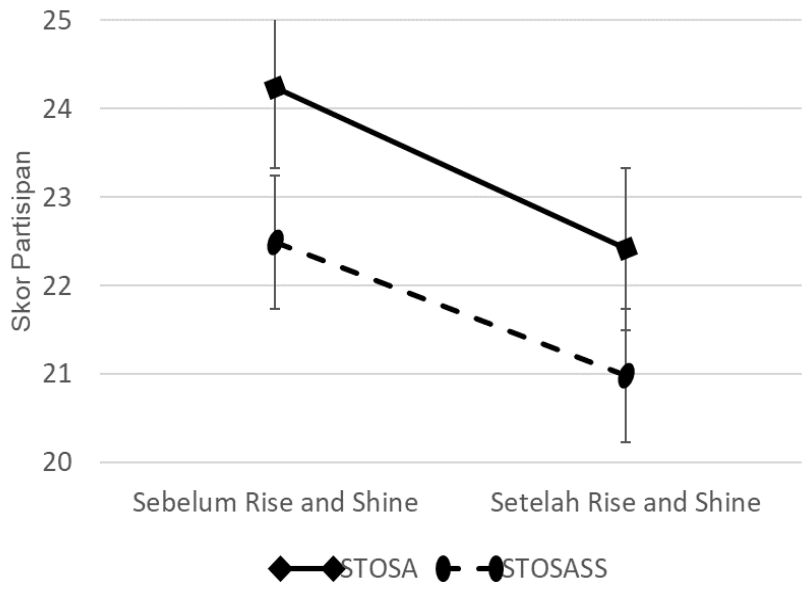

Tabel 1.

Statistik Deskriptif berdasarkan Status Kandidat Sukarelawan (Lulus vs. Tereliminasi)

\begin{tabular}{|c|c|c|c|c|}
\hline & & Status & $M$ & $S D$ \\
\hline \multirow[t]{4}{*}{ Baseline } & \multirow[t]{2}{*}{ STOSA } & Tereliminasi & 24,16 & 5,08 \\
\hline & & Lulus & 24,32 & 4,20 \\
\hline & \multirow[t]{2}{*}{ STOSASS } & Tereliminasi & 22,68 & 5,07 \\
\hline & & Lulus & 22,32 & 5,74 \\
\hline \multirow[t]{4}{*}{ Post-Program } & \multirow[t]{2}{*}{ STOSA } & Tereliminasi & 21,74 & 3,38 \\
\hline & & Lulus & 23 & 3,95 \\
\hline & \multirow[t]{2}{*}{ STOSASS } & Tereliminasi & 21 & 4,97 \\
\hline & & Lulus & 20,96 & 5,22 \\
\hline
\end{tabular}


Gambar 4.

Penurunan stigma terhadap individu yang melakukan bunuh diri pada kandidat Lightbringers yang lulus maupun tereliminasi dari pelatihan Rise and Shine.

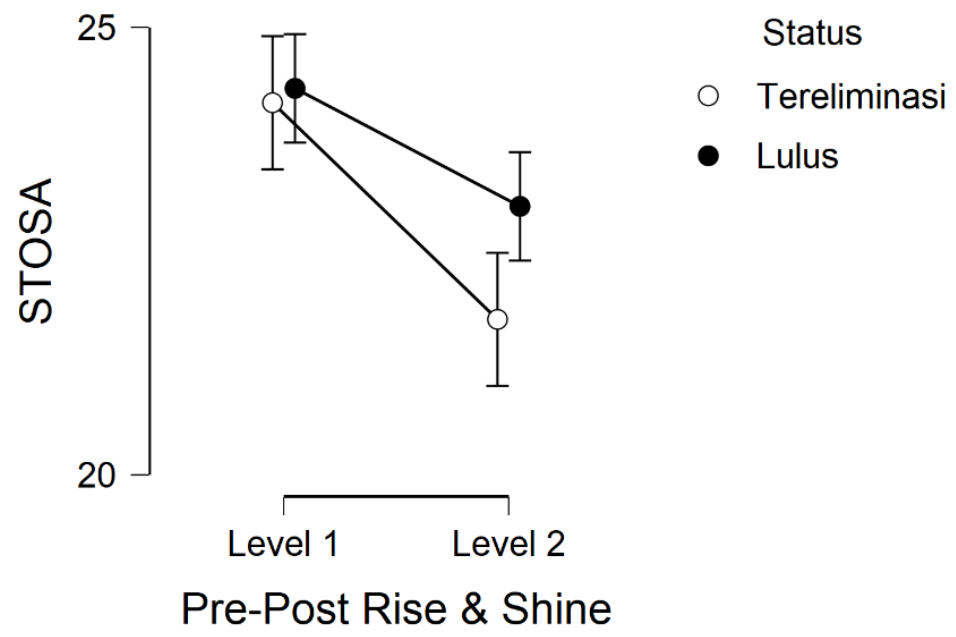

Keterangan:

Level 1 = baseline, Level 2 = post-program

Gambar 5.

Penurunan stigma terhadap individu yang ditinggalkan karena bunuh diri pada kandidat Lightbringers yang lulus maupun tereliminasi dari pelatihan Rise and Shine. Level 1 = baseline, Level 2 = post-program

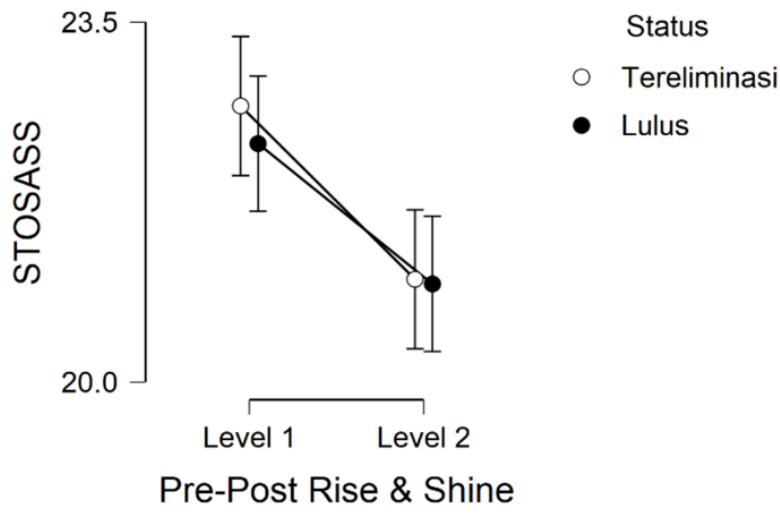

\section{Diskusi}

Penelitian ini mendukung hipotesis peneliti bahwa intervensi berupa modul pelatihan Rise and Shine terbukti menurunkan stigma terhadap penyintas percobaan maupun kehilangan karena bunuh diri pada kandidat Lightbringers, terlepas apakah mereka lulus maupun tereliminasi dari program ini. Hal ini mendukung temuan-temuan sebelumnya mengenai peran pelatihan dalam menurunkan sikap negatif terhadap masalah kesehatan jiwa, khususnya di isu bunuh diri (Hadlaczky dkk., 2014; Nejad, 2016; Reavley \& Jorm, 2013; Registered Nurses' Association of
Ontario, 2009; Samuelsson \& Åsberg, 2002; Szeto \& Dobson, 2010). Temuan yang sama didapatkan oleh Jorm, dkk. (2010), tetapi studi tersebut gagal menemukan efek jangka panjang (setelah enam bulan) terhadap penurunan stigma bunuh diri. Perhatian terhadap kurangnya bukti jangka panjang terhadap intervensi kesehatan jiwa senada dengan yang Gronholm, Henderson, Deb, dan Thornicroft (2017) kemukakan mengenai kebutuhan yang lebih besar untuk melakukan evaluasi jangka panjang terhadap intervensi di ranah tersebut. Hal ini menjadi peluang untuk penelitian lanjutan untuk mengevaluasi efek berkelanjutan Rise and Shine untuk menurunkan stigma bunuh 
diri sekaligus audit internal pelatihan bagi organisasi Into The Light Indonesia.

Klaim terhadap efektivitas pelatihan Rise and Shine untuk menurunkan stigma bunuh diri dapat dijelaskan oleh peningkatan pengetahuan dan keterampilan serta pengalaman langsung yang didapatkan kandidat Lightbringers selama pelatihan. Hal ini relevan dengan temuan Batterham, Calear, dan Christensen (2013) mengenai efek literasi terhadap stigma bunuh diri. Materi-materi yang diberikan adalah topik-topik yang merupakan hasil kajian ilmiah maupun best practice yang dilakukan organisasi lokal maupun internasional dalam usaha pencegahan bunuh diri. Beberapa sesi Rise and Shine juga menggunakan metode simulasi dan aktivitas kelompok sehingga kandidat sukarelawan mendapatkan pengalaman yang terkontrol dalam menghadapi halhal yang terkait dengan isu bunuh diri seperti manajemen informasi kematian maupun penanganan krisis bunuh diri. Peningkatan pengetahuan dan pengalaman tersebut yang dapat menjelaskan perubahan sikap negatif terhadap isu bunuh diri (Thornicroft dkk., 2016).

Peneliti dalam studi kali ini tidak melacak kandidat yang tereliminasi berakhir di materi apa sebelumnya. Dugaan penjelasan tidak berbedanya penurunan stigma antara kandidat yang lulus dan tereliminasi adalah mereka semua sudah masuk ke materi Pengantar Suicidology. Materi tersebut memberikan gambaran umum mengenai isu bunuh diri dan tiga pilar dalam pencegahan bunuh diri: pencegahan primer, intervensi krisis, dan penanganan pasca-kematian bunuh diri. Dengan sampainya sukarelawan di materi tersebut, mereka diasumsikan telah mengetahui bahwa kesehatan jiwa merupakan isu yang kompleks melalui materi-materi seperti Kesehatan Jiwa Dasar maupun Manajemen Keberagaman. Memahami bahwa isu bunuh diri merupakan fenomena yang multifaktor diduga menurunkan proses berpikir heuristik yang menjadi salah satu mekanisme pembentukan stigma bunuh diri (Griffith \& Kohrt, 2016).

Temuan tersebut juga menunjukkan potensi pelatihan Rise and Shine untuk diperluas skalanya menjadi media psikoedukasi publik untuk menurunkan stigma yang pada akhirnya mendukung strategi pencegahan bunuh diri. Sebagai sarana sosialisasi publik terhadap isu pencegahan bunuh diri, Rise and Shine dapat diadaptasi atau disesuaikan kontennya untuk dibawakan dalam platform daring untuk menjangkau masyarakat luas. Han dkk. (2018) telah melakukan studi acak terkontrol (randomized controlled trial, RCT) terhadap bentuk psikoedukasi daring untuk pencegahan bunuh diri dan menemukan bahwa bentuk intervensi tersebut meningkatkan sikap terhadap pencarian bantuan me- lalui peningkatan literasi terhadap isu bunuh diri. Harapannya dengan dilakukan di platform digital, studi lanjutan dapat mengevaluasi efektivitas pemberian materi mengenai pencegahan bunuh diri dalam skala yang lebih besar. Membawa pelatihan ini ke skala yang lebih luas juga dapat mengatasi masalah minimnya jumlah partisipan yang dimiliki oleh studi ini.

Seperti bentuk pelatihan pada umumnya, pelatihan Rise and Shine juga memberikan kontak terhadap sesama sukarelawan yang diantaranya merupakan penyintas percobaan maupun kehilangan karena bunuh diri. Studi ini tidak secara spesifik mengevaluasi efek kontak antara kandidat Lightbringers dalam rangka penurunan stigma yang terjadi sehingga berpotensi untuk melihat interaksi efek pelatihan yang diberikan dengan kontak yang terjadi. Rekomendasi tersebut didukung dua temuan, yaitu kontak dengan kelompok yang mengalami masalah kesehatan jiwa berkaitan dengan penurunan stigma terhadap isu tersebut dalam jangka pendek serta kontak melalui internet dengan orang yang memiliki isu terkait bunuh diri ber-dampak terhadap penurunan stigma bunuh diri utamanya bagi mereka yang belum pernah terpapar isu bunuh diri (Rogers, Schneider, Gai, Gorday, \& Joiner, 2018; Thornicroft, dkk., 2016).

\section{Kesimpulan}

Rise and Shine merupakan awal mula ITL mengenalkan sukarelawannya terhadap (stigma) bunuh diri dan isu-isu yang berkaitan dengannya. Studi skala kecil ini memberikan wawasan bahwa psikoedukasi terhadap isu bunuh diri memberikan dampak penurunan stigma bunuh diri sekaligus mendukung temuan-temuan sebelumnya mengenai pentingnya psikoedukasi bagi upaya pencegahan bunuh diri. Rise and Shine sebagai bentuk psikoedukasi yang mengintegrasikan modul-modul pelatihan pencegahan bunuh diri dari level individu hingga sistem kebijakan nasional berpeluang untuk memberikan pemahaman yang komprehensif me-ngenai isu bunuh diri di level individu hingga kebijakan, yang pada akhirnya akan mengurangi sikap dan respon yang keliru terkait isu bunuh diri.

\section{Keterbatasan dan Saran}

Salah satu keterbatasan studi ini merupakan hal yang secara umum menjadi implikasi dari desain penelitian, yaitu ancaman terhadap validitas internal penelitian sehubungan dengan tidak adanya randomisasi partisipan, kontrol terhadap variabel yang berpotensi mengganggu, maupun manipulasi perlakuan (Drennan, 2013). Peneliti tidak memiliki kendali untuk memantau 
pengalaman terkait isu bunuh diri selama kandidat Lightbringers angkatan kelima mengikuti sesi Rise and Shine yang diduga dapat berpengaruh terhadap stigma bunuh diri yang dimiliki partisipan. Pengalaman terkait isu bunuh diri baik yang dialami secara langsung maupun tidak langsung (menyaksikan maupun mengetahui kabar orang lain mencoba atau meninggal karena bunuh diri) memiliki dampak negatif terhadap sikap bahkan berpotensi memunculkan bunuh diri tiruan (Cerel, Maple, van de Venne, Brown, Moore, \& Flaherty, 2017).

Studi ini menekankan psikoedukasi untuk menurunkan stigma publik dan terinternalisasi yang dimiliki partisipan terhadap isu bunuh diri. Selain stigma publik, stigma pribadi (selfstigma) bunuh diri, yaitu pandangan negatif terkait diri sehubungan dengan isu bunuh yang dialami pribadi maupun sebagai penyintas kehilangan (Oexle, dkk., 2017), juga berkontribusi dalam memandang isu bunuh diri itu sendiri. Pemahaman mengenai perbedaan stigma publik dan pribadi memiliki mekanisme dan potensi masing-masing dalam usaha pencegahan bunuh diri di masyarakat. Studi yang dilakukan oleh Reynders, Kerkhof, Molenberghs, dan Van Audenhove (2015) mengemukakan perbedaan stigma publik dan pribadi dalam pengalaman individu yang pernah mencoba bunuh diri, di mana meskipun stigma publik lebih inklusif kontribusinya dalam menjelaskan percobaan bunuh diri pada laki-laki maupun perempuan sedangkan stigma pribadi hanya dialami oleh penyintas percobaan bunuh diri laki-laki. Sehubungan psikoedukasi dinilai sebagai bentuk intervensi yang dapat mengurangi stigma publik maupun pribadi, penelitian lanjutan dapat menggali apakah pelatihan Rise and Shine juga dapat mengurangi stigma pribadi di kalangan sukarelawan ITL, utamanya bagi mereka yang memiliki riwayat pemikiran hingga percobaan bunuh diri (Corrigan \& Penn, 2015).

Studi lanjutan juga dapat menggunakan desain yang membandingkan stigma bunuh diri pada kelompok kandidat Lightbringers yang melalui Rise and Shine dengan kelompok lain yang mendapatkan program ITL di luar pelatihan atau bahkan yang tidak terekspos program publik yang dilakukan ITL. Kelompok yang disebut terakhir tidak dapat berpartisipasi dalam studi kali ini sehubungan dengan kandidat Lightbringers yang tidak mengikuti seluruh sesi pelatihan/mengundurkan diri sebelum sesi pertama tidak dapat dikontak kembali. Dibandingkan Rise and Shine, program publik ITL dibawakan dalam bentuk program satu sesi (workshop) sehingga dapat ditelaah lebih lanjut mengenai perbedaan penurunan stigma antara program tersebut dengan Rise and Shine yang dibawakan sebagai materi berstruktur dengan sesi yang lebih panjang. Perbandingan antara pelatihan dengan program lainnya juga dapat menjadi sumber informasi mengenai jenis program apa yang paling berdampak terhadap penurunan stigma terhadap isu bunuh diri.

\section{Daftar Pustaka}

Batterham, P. J., Calear, A. L., \& Christensen, H. (2013). Correlates of suicide stigma and suicide literacy in the community. Suicide and Life-Threatening Behavior, 43(4), 406-417, https://doi.org/10.1111/sltb.12026

Batterham, P. J., Han, J., Calear, A. L., Anderson, J., \& Christensen, H. (2019). Suicide stigma and suicide literacy in a clinical sample. Suicide and Life-Threatening Behavior, 49(4), 1136-1147. https://doi.org/10.1111/sltb.12496

Calear, A. L., Batterham, P. J., \& Christensen, H. (2014). Predictors of help-seeking for suicidal ideation in the community: Risks and opportunities for public suicide prevention campaigns. Psychiatry Research, 219(3), 525-530, https://doi.org/10.1016/j.psychres.2014. 06.027

Carpiniello, B., \& Pinna, F. (2017). The reciprocal relationship between suicidality and stigma. Frontiers in Psychiatry, 8(35), 1-9, https://doi.org/10.3389/fpsyt.2017.0003 5

Cerel, J., Maple, M., van de Venne, J., Brown, M., Moore, M., \& Flaherty, C. (2017). Suicide exposure in the population: Perceptions of impact and closeness. Suicide and LifeThreatening Behavior, 47(6), 696-708, https://doi.org/10.1111/sltb.12333

Chapple, A., Ziebland, S., \& Hawton, K. (2015). Taboo and the different death? Perceptions of those bereaved by suicide or other traumatic death. Sociology of Health \& Illness, 37(4), 610-625, https://doi.org/10.1111/14679566.12224

Clement, S., Jarrett, M., Henderson, C., \& Thornicroft, G. (2010). Messages to use in population-level campaigns to reduce mental health-related stigma: Consensus development study. Epidemiology and Psychiatric Sciences, 19(1), 72-79, https://doi.org/10.1017/s1121189x000 01627

Coolican, H. (2014). Research methods and statistics in psychology (sixth edition). East Sussex: Psychology Press 
Corrigan, P. W., Sheehan, L., Al-Khouja, M. A., \& Stigma of Suicide Research Team. (2017). Making sense of the public stigma of suicide: Factor analyses of its stereotypes, prejudices, and discriminations. Crisis, 38(5), 351-359, https://doi.org/10.1027/02275910/a000456

Corrigan, P. W., \& Penn, D. L. (2015). Lessons from social psychology on discrediting psychiatric stigma. Stigma and Health, 1, 2-17. https://doi.org/10.1037/23766972.1.S.2

Corrigan, P. W., Morris, S. B., Michaels, P. J., Rafacz, J. D., \& Rusch, N. (2012). Challenging the public stigma of mental illness: A meta-analysis of outcome studies. Psychiatric Services, 63(10), 963973

https://doi.org/10.1176/appi.ps.201100 529

Corrigan, P. W. (2012). Where is the evidence supporting public service announcements to eliminate mental illness stigma? Psychiatric Services, 63(1), 79-82, https://doi.org/10.1176/appi.ps.201100 460

Corrigan, P. W. (2005). On the stigma of mental illness: Practical strategies for research and social change. Washington, DC: American Psychological Association

Cvinar, J. G. (2005). Do suicide survivors suffer social stigma: A review of the literature. Perspectives in Psychiatric Care, 41(1), 14-21

Dare, A. J., Andriessen, K. A., Nordentoft, M., Meier, M., Huisman, A., \& Pirkis, J. E. (2011). Media awards for responsible reporting of suicide: Experiences from Australia, Belgium and Denmark. International Journal of Mental Health Systems, 5(1), 15-21, https://doi.org/10.1186/1752-4458-515

Drennan, J. (2013). Quasi-experimental and retrospective pretest designs for health care research. In E. A. Curtis, \& J. Drennan (Eds.). Quantitative health research: Issues and methods (pp. 197-220). Berkshire: Open University Press

Dueweke, A. R., \& Bridges, A. J. (2017). The effects of brief, passive psychoeducation on suicide literacy, stigma, and attitudes toward help-seeking among Latino immigrants living in the United States. Stigma and Health, 2(1), 28, https://doi.org/10.1037/sah0000038

Feigelman, W., Gorman, B. S., \& Jordan, J. R. (2009). Stigmatization and suicide bereavement, Death Studies, 33(7), 591608 ,

https://doi.org/10.1080/074811809029 79973

Fitzpatrick, S. J., Hooker, C., \& Kerridge, I. (2015). Suicidology as a social practice, Social Epistemology, 29(3), 303-322, https://doi.org/10.1080/02691728.2014 .895448

Frey, L. M. (2015). Mental health among suicide attempt survivors: The roles of stigma, self-disclosure, and family reactions. Dissertations of Family Sciences, University of Kentucky. Retrieved from: http://uknowledge.uky.edu/hes_etds/29

Griffith, J. L., \& Kohrt, B. A. (2016). Managing stigma effectively: What social psychology and social neuroscience can teach us. Academic Psychiatry, 40(2), 339-347, https://doi.org/10.1007/s40596-0150391-0.

Gronholm, P. C., Henderson, C., Deb, T., \& Thornicroft, G. (2017). Interventions to reduce discrimination and stigma: the state of the art. Social Psychiatry and Psychiatric Epidemiology, 52(3), 249258., https://doi.org/10.1007/s00127017-1341-9

Hadlaczky, G., Hökby, S., Mkrtchian, A., Carli, V., \& Wasserman, D. (2014). Mental Health First Aid is an effective public health intervention for improving knowledge, attitudes, and behaviour: A meta-analysis. International Review of Psychiatry, 26(4), 467-475,

https://doi.org/10.3109/09540261.2014 .924910

Han, J., Batterham, P. J., Calear, A. L., Wu, Y., Xue, J., \& van Spijker, B. A. J. (2018). Development and pilot evaluation of an online psychoeducational program for suicide prevention among university students: A randomised controlled trial. Internet Interventions, 12, 111-120, https://doi.org/10.1016/j.invent.2017.11 .002

John, A., Hawton, K., Lloyd, K., Luce, A., Platt, S., Scourfield, J., Marchant, A. L., Jones, P. A., \& Dennis, M. S. (2014). PRINTQUAL: A Measure for Assessing the Quality of Newspaper Reporting of Suicide. Crisis, 35(6), https://doi.org/10.1027/02275910/a000276

Jorm, A. F., Kitchener, B. A., Sawyer, M. G., Scales, H., \& Cvetkovski, S. (2010). Mental health first aid training for high school teachers: A cluster randomized trial. BMC Psychiatry, 10(51), 1-12, 
https://doi.org/10.1186/1471-244x-1051

Klimes-Dougan, B., Yuan, C., Lee, S., \& Houri, A. K. (2009). Suicide prevention with adolescents: Considering potential benefits and untoward effects of public service announcements. Crisis, 30(3):128-135,

https://doi.org/10.1027/0227-

5910.30.3.128

Lester, D., \& Walker, R. L. (2006). The stigma for attempting suicide and the loss to suicide prevention efforts. Crisis: The Journal of Crisis Intervention and Suicide Prevention, 27(3), 147-148. https://doi.org/10.1027/0227-

5910.27.3.147

Loreto, N. (2017). Reducing stigma and encouraging help seeking intentions through a mental health literacy program. Dissertation of Faculty of Psychology, Walden University

Macintyre, A., Ferris, D., Gonçalves, B., \& Quinn, N. (2018). What has economics got to do with it? The impact of socioeconomic factors on mental health and the case for collective action. Palgrave Communications, 4(1), 15. https://doi.org/10.1057/s41599-0180063-2

Maunder, R. D., \& White, F. A. (2019). Intergroup contact and mental health stigma: A comparative effectiveness metaanalysis. Clinical psychology review, 72, 101749.

https://doi.org/10.1016/j.cpr.2019.1017 49

Muehlenkamp, J. J., \& Thoen, S. K. (2019). Shortand long-term impact of an undergraduate suicidology course. Suicide and LifeThreatening Behavior, 49(6), 1573-1586, https://doi.org/10.1111/sltb.12552

Nejad, N. S. (2016). Social workers' education, training, and experience in practice with clients bereaved by suicide death. Theses, Dissertations, and Projects. 1747. Retrieved from: https://scholarworks.smith.edu/theses/1 747

Oexle, N., Waldmann, T., Staiger, T., Xu, Z., \& Rüsch, N. (2018a). Mental illness stigma and suicidality: the role of public and individual stigma. Epidemiology and Psychiatric Sciences, 27, 169-175, https://doi.org/10.1017/S20457960160 00949

Oexle, N., Herrmann, K., Staiger, T., Sheehan, L., Rüsch, N., \& Krumm, S. (2018b). Stigma and suicidality among suicide attempt survivors: A qualitative study. Death
Studies,

1-8, https://doi.org/10.1080/07481187.2018 1474286

Oexle, N., Rüsch, N., Viering, S., Wyss, C., Seifritz, E., Xu, Z., \& Kawohl, W. (2017). Self-stigma and suicidality: a longitudinal study. European archives of psychiatry and clinical neuroscience, 267(4), 359-361, https://doi.org/10.1007/s00406-0160698-1

Pettigrew, T. F., \& Tropp, L. R. (2006). A metaanalytic test of intergroup contact theory. Journal of Personality and Social Psychology, 90, 751-783, https://doi.org/10.1037/00223514.90.5.751

Reavley, N. J., \& Jorm, A. F. (2013). Community and population-based interventions to reduce stigma associated with depression, anxiety and suicide: A rapid review. Melbourne: Sax Institute

Registered Nurses' Association of Ontario (RNAO). (2009). Assessment and care of adults with suicidal ideation and behaviour. Retrieved from http://rnao.ca/bpg/guidelines/assessme nt-and-care-adults-risk-suicidal-ideationand-behaviour

Reynders, A., Kerkhof, A. J., Molenberghs, G., \& Van Audenhove, C. (2015). Help-seeking, stigma and attitudes of people with and without a suicidal past: A comparison between a low and a high suicide rate country. Journal of Affective Disorders, 178,

5-11, https://doi.org/10.1016/j.jad.2015.02.01 3

Rogers, M. L., Schneider, M. E., Gai, A. R., Gorday, J. Y., \& Joiner, T. E. (2018). Evaluation of two web-based interventions in reducing the stigma of suicide. Behaviour Research and Therapy, 109, 49-55, https://doi.org/10.1016/j.brat.2018.08.0 01

Samuelsson, M., \& Åsberg, M. (2002). Training program in suicide prevention for psychiatric nursing personnel enhance attitudes to attempted suicide patients. International Journal of Nursing Studies, $39(1)$,

115-121, https://doi.org/10.1016/s00207489(00)00110-3

Sand, E., Gordon, K. H., \& Bresin, K. (2013). The impact of specifying suicide as the cause of death in an obituary. Crisis, 34(1), 63-66, https://doi.org/10.1027/02275910/a000154

Scocco, P., Castriotta, C., Toffol, E., \& Preti, A. (2012). Stigma of suicide attempt (STOSA) 
scale and stigma of suicide and suicide survivor (STOSASS) scale: Two new assessment tools. Psychiatry Research, 200, 872-878, https://doi.org/10.1016/j.psychres.2012. 06.033

Sheehan, L., Corrigan, P. W., Al-Khouja, M. A., Lewy, S. A., Major, D. R., Mead, J., Redmon, M., Rubey, C. T., \& Weber, S. (2018). Behind closed doors: The stigma of suicide loss survivors. OMEGA-Journal of Death and Dying, $\quad 77(4) \quad 330-349$, https://doi.org/10.1177/003022281667 4215

Sheehan, L., Dubke, R., \& Corrigan, P. W. (2017). The specificity of public stigma: A comparison of suicide and depressionrelated stigma. Psychiatry Research, 256, 40-45,

https://doi.org/10.1016/j.psychres.2017. 06.015

Sihombing, S. O. (2014). The Indonesian values scale: An empirical assessment of the short-form scale. Makara Human Behavior Studies In Asia, 18(2), 97-108. https://doi.org/10.7454/mssh.v18i2.346 5

Szeto, A. C. H., \& Dobson, K. S. (2010). Reducing the stigma of mental disorders anti-stigma at work: A review of current workplace intervention programs. Applied and Preventive Psychology, 14, 41-56, https://doi.org/10.1016/j.appsy.2011.11. 002
Taylor-Rodgers, E., \& Batterham, P. J. (2014). Evaluation of an online psychoeducation intervention to promote mental health help seeking attitudes and intentions among young adults: randomised controlled trial.Journal of affective disorders, 168, 65-71. https://doi.org/10.1016/j.jad.2014.06.04 7

Thornicroft, G., Mehta, N., Clement, S., EvansLacko, S., Doherty, M. Rose, D., Koschorke, M., Shidhaye, R., O'Reilly, C., \& Henderson, C. (2016). Evidence for effective interventions to reduce mental-healthrelated stigma and discrimination. The Lancet, 387 (10023), 1123-1132, https://doi.org/10.1016/S01406736(15)00298-6

Wilson, B., \& Neufeld, E. (2017). The safeTALK suicide training: An evaluation of attitudes and actions among medical students. Res Medica - Journal of the Royal Medical Society, 24(1), 4-16, https://doi.org/10.2218/resmedica.v24i 1.1538

World Health Organization. Regional Office for South-East Asia. (2017). Mental health status of adolescents in South-East Asia: Evidence for action. World Health Organization. Regional Office for SouthEast Asia. Retrieved from: https://apps.who.int/iris/handle/10665 /254982 


\section{Lampiran A}

Detail Materi Rise and Shine

\begin{tabular}{|c|c|c|c|}
\hline Sesi & Nama Materi & Tujuan Materi & $\begin{array}{c}\text { Metode } \\
\text { Penyampaian } \\
\end{array}$ \\
\hline 1 & $\begin{array}{l}\text { Berpikir Kritis \& } \\
\text { Pengantar } \\
\text { Metode } \\
\text { Penelitian }\end{array}$ & $\begin{array}{l}\text { 1. Memberikan wawasan mengenai pentingnya } \\
\text { berpikir kritis dalam memahami gejala sosial dan } \\
\text { tingkah laku } \\
\text { 2. Memberikan pengantar mengenai ragam cara } \\
\text { memahami tingkah laku } \\
\text { 3. Memberikan pengantar mengenai metode riset } \\
\text { empiris yang menjadi landasan ilmiah dalam } \\
\text { memahami tingkah laku }\end{array}$ & $\begin{array}{ll}\text { 1. } & \text { Ceramah } \\
\text { 2. } & \text { Diskusi \& } \\
& \text { Tanya Jawab } \\
\text { 3. } & \text { Simulasi }\end{array}$ \\
\hline 2 & Wicara Publik & $\begin{array}{l}\text { 1. Memberikan dasar-dasar wicara publik dan } \\
\text { memahami audiens } \\
\text { 2. Mengetahui cara-cara menyesuaikan mode } \\
\text { wicara publik dengan karakteristik audiens }\end{array}$ & $\begin{array}{ll}\text { 1. } & \text { Ceramah } \\
\text { 2. } & \text { Diskusi \& Tanya } \\
\text { Jawab } \\
\text { 3. Simulasi Wicara } \\
\text { Publik }\end{array}$ \\
\hline 3 & $\begin{array}{l}\text { Kesehatan Jiwa } \\
\text { Dasar \& Self-care }\end{array}$ & $\begin{array}{l}\text { 1. Memberikan pengetahuan awal mengenai isu } \\
\text { masalah kesehatan jiwa, psikopatologi, dan } \\
\text { relevensinya dengan isu bunuh diri } \\
\text { 2. Memberikan tips dan trik sederhana mengenai } \\
\text { bagaimana seseorang dapat menjaga kondisi } \\
\text { kesehatan jiwanya }\end{array}$ & $\begin{array}{ll}\text { 1. } & \text { Presentasi } \\
& \text { Kelompok } \\
\text { 2. } & \text { Diskusi \& Tanya } \\
& \text { Jawab }\end{array}$ \\
\hline 4 & Profil Komunitas & $\begin{array}{l}\text { 1. Memahami profil dan filosofi berdirinya Into } \\
\text { The Light Indonesia } \\
\text { 2. Memahami kondisi masalah kesehatan jiwa, } \\
\text { pencegahan bunuh diri, dan relasinya dengan isu } \\
\text { kesehatan lainnya di Indonesia }\end{array}$ & $\begin{array}{ll}\text { 1. } & \text { Ceramah } \\
\text { 2. } & \text { Diskusi \& Tanya } \\
& \text { Jawab }\end{array}$ \\
\hline 5 & $\begin{array}{l}\text { Manajemen } \\
\text { Keberagaman }\end{array}$ & $\begin{array}{l}\text { 1. Memahami bagaimana prasangka, privilese dan } \\
\text { penindasan bekerja } \\
\text { 2. Menghargai perbedaan dan keberagaman dalam } \\
\text { kelompok dan individu }\end{array}$ & $\begin{array}{ll}\text { 1. } & \text { Ceramah } \\
\text { 2. } & \text { Diskusi \& Tanya } \\
\text { Jawab } \\
\text { 3. } \\
\text { Aktivitas } \\
\text { Kelompok } \\
\end{array}$ \\
\hline 6 & $\begin{array}{l}\text { Pengantar } \\
\text { Suicidology }\end{array}$ & $\begin{array}{l}\text { 1. Memahami mitos dan fakta bunuh diri } \\
\text { 2. Memahami sejarah perspektif masyarakat dari } \\
\text { zaman peradaban kuno hingga modern mengenai } \\
\text { bunuh diri } \\
\text { 3. Memahami kajian teoretis mengenai bunuh diri } \\
\text { dan mengaplikasikannya pada kasus } \\
\text { pendampingan, pengembangan program dan diri } \\
\text { sendiri }\end{array}$ & $\begin{array}{ll}\text { 1. } & \text { Ceramah } \\
\text { 2. Diskusi \& Tanya } \\
\text { Jawab } \\
\text { 3. Presentasi } \\
\text { Kelompok }\end{array}$ \\
\hline 7 & $\begin{array}{l}\text { Pencegahan } \\
\text { Primer Bunuh } \\
\text { Diri I: } \\
\text { Pengembangan } \\
\text { Program Publik }\end{array}$ & $\begin{array}{l}\text { 1. Peserta memahami dasar tahapan pencegahan } \\
\text { bunuh diri primer } \\
\text { 2. Peserta memahami dasar pengembangan } \\
\text { program pencegahan bunuh diri } \\
\text { 3. Peserta mampu untuk merancang, } \\
\text { mengembangkan dan mengevaluasi program } \\
\text { untuk pencegahan bunuh diri dan kesehatan jiwa }\end{array}$ & $\begin{array}{ll}\text { 1. } & \text { Ceramah } \\
\text { 2. } & \text { Diskusi \& Tanya } \\
& \text { Jawab }\end{array}$ \\
\hline
\end{tabular}




\begin{tabular}{|c|c|c|c|}
\hline Sesi & Nama Materi & Tujuan Materi & $\begin{array}{c}\text { Metode } \\
\text { Penyampaian }\end{array}$ \\
\hline 8 & $\begin{array}{l}\text { Pencegahan } \\
\text { Primer Bunuh } \\
\text { Diri II: } \\
\text { Keterampilan } \\
\text { Advokasi }\end{array}$ & $\begin{array}{l}\text { 1. Memahami cakupan layanan dan masalah } \\
\text { sistem kesehatan jiwa di Indonesia } \\
\text { 2. Mengetahui dasar dan teknik-teknik advokasi } \\
\text { 3. Memiliki kemampuan advokasi sistem } \\
\text { kesehatan jiwa }\end{array}$ & $\begin{array}{ll}\text { 1. } & \text { Ceramah } \\
\text { 2. } & \text { Diskusi \& Tanya } \\
& \text { Jawab } \\
\text { 3. } & \text { Simulasi Praktik } \\
& \text { Advokasi }\end{array}$ \\
\hline 9 & $\begin{array}{l}\text { Intervensi Krisis } \\
\text { Bunuh Diri I: } \\
\text { (Krisis) Tatap } \\
\text { Muka }\end{array}$ & $\begin{array}{l}\text { 1. Memahami dasar krisis intervensi dan rujukan } \\
\text { ke profesional } \\
\text { 2. Melakukan penilaian kehendak bunuh diri } \\
\text { melalui proses pendampingan } \\
\text { 3. Melakukan penanganan individu dengan } \\
\text { kecenderungan bunuh diri }\end{array}$ & $\begin{array}{ll}\text { 1. } & \text { Ceramah } \\
\text { 2. } & \text { Diskusi \& Tanya } \\
\text { Jawab } \\
\text { 3. Simulasi } \\
\text { Pendampingan } \\
\text { Tatap Muka }\end{array}$ \\
\hline 10 & $\begin{array}{l}\text { Intervensi Krisis } \\
\text { Bunuh Diri I: } \\
\text { Intervensi via } \\
\text { Medium (Chat, } \\
\text { Telepon, Email) }\end{array}$ & $\begin{array}{l}\text { 1. Melakukan intervensi krisis bunuh diri tanpa } \\
\text { tatap muka } \\
\text { 2. Menunjukkan sensitivitas pemaknaan bunuh } \\
\text { diri dalam beragam perspektif }\end{array}$ & $\begin{array}{ll}\text { 1. } & \text { Ceramah } \\
\text { 2. } & \text { Diskusi \& Tanya } \\
& \text { Jawab } \\
\text { 3. } & \text { Simulasi } \\
& \text { Pendampingan } \\
& \text { melalui Medium } \\
& \text { Teknologi } \\
\end{array}$ \\
\hline 11 & $\begin{array}{l}\text { Kegawatdarurat } \\
\text { an Psikiatrik }\end{array}$ & $\begin{array}{l}\text { 1. Mengetahui prosedur kegawatdaruratan pada } \\
\text { kasus kesehatan jiwa, terutama yang terkait } \\
\text { dengan isu bunuh diri }\end{array}$ & $\begin{array}{l}\text { 1. Ceramah } \\
\text { 2. Diskusi \& Tanya } \\
\text { Jawab }\end{array}$ \\
\hline 12 & $\begin{array}{l}\text { Pencegahan } \\
\text { Bunuh Diri } \\
\text { Pasca-kematian } \\
\text { (Postvention) I: } \\
\text { Duka \& } \\
\text { Manajemen } \\
\text { Kehilangan }\end{array}$ & $\begin{array}{l}\text { 1. Mengetahui manajemen krisis yang tepat } \\
\text { setelah terjadi sebuah kematian akibat bunuh diri } \\
\text { dalam sebuah komunitas/organisasi } \\
\text { 2. Mampu mendampingi rekan dan penyintas dari } \\
\text { orang yang bunuh diri } \\
\text { 3. Memahami cara menghindari terjadinya } \\
\text { tindakan bunuh diri imitasi }\end{array}$ & $\begin{array}{ll}\text { 1. } & \text { Ceramah } \\
\text { 2. } & \text { Diskusi \& Tanya } \\
& \text { Jawab } \\
\text { 3. } & \text { Analisis Berita } \\
\text { Bunuh Diri } \\
\text { 4. } & \text { Simulasi Press } \\
& \text { Release \& } \\
& \text { Manajemen } \\
& \text { Krisis Pasca- } \\
\text { kematian }\end{array}$ \\
\hline 13 & $\begin{array}{l}\text { Pencegahan } \\
\text { Bunuh Diri } \\
\text { Pasca-kematian } \\
\text { (Postvention) II: } \\
\text { Pengembangan } \\
\text { Program Publik }\end{array}$ & $\begin{array}{l}\text { 1. Melakukan upaya suicide postvention pada } \\
\text { tingkatan komunitas dan individual dalam } \\
\text { berbagai konteks dengan mempertimbangkan } \\
\text { bukti ilmiah, sensitivitas budaya dan hak asasi } \\
\text { manusia }\end{array}$ & $\begin{aligned} & \text { 1. } \text { Simulasi } \\
& \text { Manajemen } \\
& \text { Krisis Individu } \\
& \text { 2. } \text { Simulasi } \\
& \text { Manajemen } \\
& \text { Media Massa } \\
& \text { 3. } \text { Simulasi } \\
& \text { Manajemen } \\
& \text { Pemangku } \\
& \text { Kepentingan } \\
&\end{aligned}$ \\
\hline 14 & $\begin{array}{l}\text { Evaluasi } \\
\text { Program Kerja: } \\
\text { Budgeting dan } \\
\text { Aspek Finansial }\end{array}$ & $\begin{array}{l}\text { 1. Mengetahui aspek penting dalam membuat } \\
\text { rencana maupun evaluasi finansial dari sebuah } \\
\text { program kerja }\end{array}$ & $\begin{array}{ll}\text { 1. } & \text { Ceramah } \\
\text { 2. } & \text { Simulasi } \\
& \text { Budgeting \& } \\
& \text { Evaluasi } \\
& \text { Finansial } \\
\end{array}$ \\
\hline
\end{tabular}

